\title{
Ultrathin Tropical Tropopause Clouds (UTTCs): I. Cloud morphology and occurrence
}

\author{
Th. Peter ${ }^{1}$, B. P. Luo ${ }^{1}$, M. Wirth ${ }^{2}$, C. Kiemle ${ }^{2}$, H. Flentje ${ }^{2}$, V. A. Yushkov ${ }^{3}$, V. Khattatov ${ }^{3}$, V. Rudakov ${ }^{3}$, A. Thomas ${ }^{4}$, \\ S. Borrmann ${ }^{4}$, G. Toci ${ }^{5}$, P. Mazzinghi ${ }^{6}$, J. Beuermann ${ }^{7}$, C. Schiller ${ }^{7}$, F. Cairo ${ }^{8}$, G. Di Donfrancesco ${ }^{9}$, A. Adriani ${ }^{8}$, \\ C. M. Volk ${ }^{10}$, J. Strom ${ }^{11}$, K. Noone ${ }^{12}$, V. Mitev ${ }^{13}$, R. A. MacKenzie ${ }^{14}$, K. S. Carslaw ${ }^{15}$, T. Trautmann ${ }^{16}$, \\ V. Santacesaria ${ }^{17}$, and L. Stefanutti ${ }^{18}$ \\ ${ }^{1}$ Institute for Atmospheric and Climate Science, ETH Zurich, Switzerland \\ ${ }^{2}$ Institute for Atmospheric Physics, DLR Oberpfaffenhofen, Germany \\ ${ }^{3}$ Central Aerological Observatory, Moscow, Russia \\ ${ }^{4}$ Institute for Atmospheric Physics, University of Mainz, Germany \\ ${ }^{5}$ Quantum Electronics Institute, National Research Council (IEQ-CNR), Florence, Italy \\ ${ }^{6}$ National Institute of Applied Optics, Florence, Italy \\ ${ }^{7}$ Institute I: Stratosphere, Forschungszentrum Jülich GmbH, Jülich, Germany \\ ${ }^{8}$ Institute for Atmospheric Science and Climate,CNR, Roma, Italy \\ ${ }^{9}$ ENEA Casaccia, Roma, Italy \\ ${ }^{10}$ Institut fr Meteorologie und Geophysik, Universität Frankfurt, Germany \\ ${ }^{11}$ Institute of Applied Environmental Research, Stockholm University, Sweden \\ ${ }^{12}$ Department of Meteorology, Stockholm University, Sweden \\ ${ }^{13}$ Observatoire cantonal, Neuchâtel, Switzerland \\ ${ }^{14}$ Environmental Science Department, Lancaster University, UK \\ ${ }^{15}$ School of the Environment, University of Leeds, UK \\ ${ }^{16}$ Institute of Meteorology, University of Leipzig, Germany \\ ${ }^{17}$ IROE - CNR 11Nello Carrara", Firenze, Italy \\ ${ }^{18}$ Geophysica-GEIE - CNR", Firenze, Italy
}

Received: 9 December 2002 - Published in Atmos. Chem. Phys. Discuss.: 19 March 2003

Revised: 25 June 2003 - Accepted: 25 June 2003 - Published: 29 July 2003

\begin{abstract}
Subvisible cirrus clouds (SVCs) may contribute to dehydration close to the tropical tropopause. The higher and colder SVCs and the larger their ice crystals, the more likely they represent the last efficient point of contact of the gas phase with the ice phase and, hence, the last dehydrating step, before the air enters the stratosphere. The first simultaneous in situ and remote sensing measurements of SVCs were taken during the APE-THESEO campaign in the western Indian ocean in February/March 1999. The observed clouds, termed Ultrathin Tropical Tropopause Clouds (UTTCs), belong to the geometrically and optically thinnest large-scale clouds in the Earth's atmosphere. Individual UTTCs may exist for many hours as an only 200-300 m thick cloud layer just a few hundred meters below the tropical cold point tropopause, covering up to $10^{5} \mathrm{~km}^{2}$. With temperatures as low as $181 \mathrm{~K}$ these clouds are prime representatives for defining the water mixing ratio of air entering the lower stratosphere.
\end{abstract}

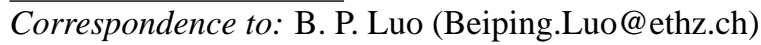

\section{Introduction}

Cirrus clouds are an essential element in the Earth's radiation budget due to their direct radiative forcing and their influence on the water budget in the middle and upper troposphere (Lohmann and Roeckner, 1995). Cirrus clouds in the vicinity of the tropical tropopause regions might in part be responsible for the dehydration of the uppermost troposphere and therefore also for the water vapor mixing ratio in the lower stratosphere (Jensen et al., 1996 and 2001; Sherwood and Dessler, 2000; Gettelman et al., 2001). For cirrus clouds with particularly thin optical thickness, $\tau$, Sassen et al. (1989) coined the term Subvisible Cirrus (SVC), and used $\tau<0.03$ as a visibility criterion. Previous studies have found SVCs with optical thicknesses typically in the range $10^{-3}-10^{-2}$ (Heymsfield, 1986; Heymsfield and McFarquhar; 1996; Winker and Trepte, 1998; Wang et al., 1998; McFarquhar et al., 2000; Omar and Gardner, 2001), with occurrence frequencies vanishing rapidly at even lower optical 


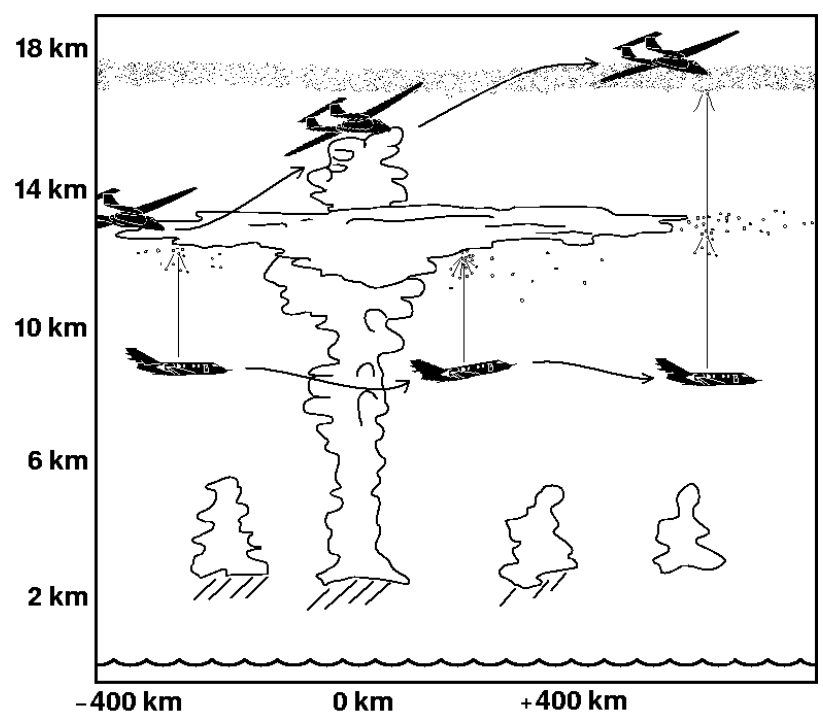

Fig. 1. Sketch of flight strategy of the Falcon (below $12 \mathrm{~km}$ ) and the Geophysica (up to $21 \mathrm{~km}$ ). Both aircraft can travel at the same speed. On line evaluation of the Falcon lidar measurements allows to maneuver the Geophysica into extremely thin clouds, e.g. the UTTC shown at $17 \mathrm{~km}$, which remain invisible to the Geophysica pilot.

thicknesses. First emerging climatological information on laminar cirrus based on remote (lidar, satellite) and in situ (aircraft) retrievals suggest that they are probably ubiquitous in the tropics independent of seasons (e.g. Wang et al., 1998; McFarquhar et al., 2000; Winker andTrepte, 1998).

In February and March 1999, the European airborne campaign APE-THESEO was performed from the Seychelles, $5^{\circ} \mathrm{S} 55^{\circ} \mathrm{E}$, with the aim to investigate the effects of deep convective events and of cirrus on the Upper Troposphere/Lower Stratosphere (UTLS) water budget in the western Indian ocean. This paper describes the morphology and occurrence frequencies of the particularly thin and high SVCs observed during APE-THESEO. The underlying particle counter measurements are described by Thomas et al. (2002). The details of the formation process of these clouds, how they are maintained, and to what degree they may lead to dehydration of the upper troposphere and lower stratosphere is still uncertain. A mechanism for their maintenance and stabilization is described in the companion paper (Luo et al., 2003a). Upon cooling UTTCs are prone to dehydrating the air before it enters the tropical stratosphere, a mechanism described by Luo et al. (2003b).

\section{APE-THESEO flight strategy}

Two aircraft were employed during APE-THESEO and closely coordinated with each other: the low-flying Falcon, a German research aircraft equipped with a three-wave-lengths lidar system (1064, 532, $354 \mathrm{~nm}$ backscatter ratios; $532 \mathrm{~nm}$ depolarization ratio), and the high-flying Geophysica, a Russian research aircraft with various in-situ and short-range remote instruments for measuring particles (size distributions, water and nitric acid in the condensed phase, backscatter in-situ and between $300 \mathrm{~m}$ and $2500 \mathrm{~m}$ above the aircraft) and trace gases (gas phase water, ozone, $\mathrm{CO}, \mathrm{N}_{2} \mathrm{O}, \mathrm{CFC}-11$, CFC-12, SF 6 ). See Table 1 for an overview. For more detailed descriptions of the Falcon lidar system see Wirth and Renger (1996) and of the Geophysica payload see Stefanutti et al. (1999).

The tandem deployment of the Falcon and the Geophysica has some unique features. The Falcon lidar system allows the detection of extremely thin cirrus structures, which can neither be observed by ground-based lidar nor by the pilot of the high-flying aircraft. At $1064 \mathrm{~nm}$ wavelength the backscatter ratio is a sensitive indicator of the presence of thin clouds or aerosol layers, even when the simultaneous backscatter measurements at $532 \mathrm{~nm}$ and $354 \mathrm{~nm}$ show practically no indication of a thin cloud feature. This is due to the lower Rayleigh backscatter by the air molecules $\left(\propto \lambda^{-4}\right)$, while the backscatter of ice particles is nearly independent of wavelength as the particles are much larger than all wavelengths. The lidar information is available as on-line quick-look information during the flight. Owing to these capabilities the Falcon served as pathfinder for the Geophysica during APE-THESEO. The high flexibility of the Geophysica allows direct changes of altitude and flight direction according to inflight requests by the mission scientist onboard the Falcon, e.g. for obtaining controlled changes in altitude in steps of $50 \mathrm{~m}$. The Falcon, when throttled, can fly with the same speed (relative to ground) at $10-12 \mathrm{~km}$ as the Geophysica at $16-20 \mathrm{~km}$, allowing simultaneous measurements on the same object, see Fig. 1. Alternatively, the Falcon can fly ahead with increasing distance from Geophysica when new space is to be explored. For more information on the tandem flight options during APE-THESEO and during other campaigns see Peter et al. (2000).

The simultaneous remote sensing lidar measurement and the in-situ measurements provide new quantitative information on the microphysical and optical properties of cirrus clouds in the $3-4 \mathrm{~km}$ below the cold point tropopause, the so-called Tropical Tropopause Layer, TTL (Sherwood and Dessler, 2000). Clouds with a wide range of backscattering ratios and various amounts of condensed water content were found. Besides SVCs and thicker visible cirrus clouds (Santacesaria et al., 2003), UTTCs were detected and could be characterized as a new, distinct class of ultrathin clouds with extremely low optical thickness, $\tau<10^{-3}$ (Luo et al., 2003b). 
Table 1. M-55 Geophysica Scientific Payload during the APE-THESEO campaign

\begin{tabular}{|c|c|}
\hline In situ & Remote Sensing \\
\hline \multicolumn{2}{|l|}{ Aerosol Instruments } \\
\hline $\begin{array}{l}\text { FSSP-300 } \\
\text { Forward Scattering Spectrometer Probe to measure aerosol size distribu- } \\
\text { tion in the range } 0.1-20 \mu \mathrm{m} \text {. }\end{array}$ & \multirow{2}{*}{\begin{tabular}{|l} 
MAL \\
Low-power (micro-joule) lidar \\
to measure $532 \mathrm{~nm}$ backscatter \\
and depolarization ratios \\
within $1 \mathrm{~km}$ above the aircraft.
\end{tabular}} \\
\hline $\begin{array}{l}\text { MAS } \\
\text { Miniaturized Aerosol Sampler (backscatter sonde) to measure } 532 \mathrm{~nm}\end{array}$ & \\
\hline backscatter and depolarization in the immediate vicinity of the aircraft. & \multirow{3}{*}{$\begin{array}{l}\text { ABLE } \\
\text { High-power aerosol lidar } 532 \\
\text { nm, } 355 \mathrm{~nm} \text {, upward or down- } \\
\text { ward looking. }\end{array}$} \\
\hline $\begin{array}{l}\text { CVI-Package } \\
\text { Counter-flow Virtual Impactor to measure particles having a diameter } \\
\text { larger than a critical value, which are then heated and evaporate. Eva- }\end{array}$ & \\
\hline $\begin{array}{l}\text { poration products are then analyzed by: } \\
\text { Ly- } \alpha \text { water } \\
\text { Lyman-alpha instrument to measure the condensed phase water; } \\
\text { TDL } \\
\text { Tunable Diode Laser absorption spectroscopy for } \mathrm{HNO}_{3} \text { and } \mathrm{H}_{2} \mathrm{O} \text {. }\end{array}$ & \\
\hline \multicolumn{2}{|l|}{ Chemical Instruments } \\
\hline $\begin{array}{l}\text { FLASH } \\
\text { Ly- } \alpha \text { hygrometer to measure water vapor in the uppermost troposphere } \\
\text { and lower stratosphere; only gas phase, no condensed-phase water. }\end{array}$ & \multirow{2}{*}{$\begin{array}{l}\text { GASCOD } \\
\text { UV-visible spectrometer to } \\
\text { measure vertical columns of } \\
\mathrm{O}_{3} \text { and } \mathrm{NO}_{2} \text {, also suited to } \\
\text { measure the upward and } \\
\text { downward radiation fluxes. }\end{array}$} \\
\hline $\begin{array}{l}\text { FISH } \\
\text { Ly- } \alpha \text { hygrometer to measure water vapor in the UTLS, measures gas } \\
\text { phase water plus condensed-phase water (enhanced by a factor } 5 \text { ). }\end{array}$ & \\
\hline $\begin{array}{l}\text { ACH } \\
\text { Frost point hygrometer. }\end{array}$ & \multirow{2}{*}{$\begin{array}{l}\text { SORAD } \\
\text { Solar radiometer to measure } \\
\text { the integrated solar flux from } \\
\text { the near UV to the near IR. }\end{array}$} \\
\hline $\begin{array}{l}\text { FOZAN } \\
\text { Chemiluminescent ozone sensor to detect fast ozone } \mathrm{v}\end{array}$ & \\
\hline $\begin{array}{l}\text { ECOC } \\
\text { Modified electrochemical ozone sonde. }\end{array}$ & \\
\hline $\begin{array}{l}\text { HAGAR } \\
\text { Gas chromatograph to measure } \mathrm{N}_{2} \mathrm{O}, \mathrm{SF}_{6}, \mathrm{CFC}-11\end{array}$ & \\
\hline
\end{tabular}

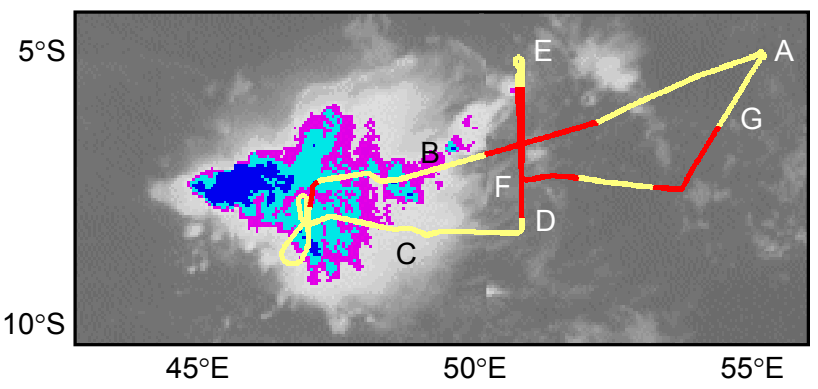

Fig. 2. Meteosat cloud image of western Indian ocean on 24 February 1999 showing a tropical thunderstorm centered at $8^{\circ} \mathrm{S} 46^{\circ} \mathrm{E}$, about $1000 \mathrm{~km}$ southwest of the Seychelles at $5^{\circ} \mathrm{S} 55^{\circ} \mathrm{E}$ (point A). Colors indicate brightness temperatures (i.e. approximately the temperature at the altitude below which the cloud becomes optically thick in the infrared): pink below $213 \mathrm{~K}$; light blue below $208 \mathrm{~K}$; dark blue below $203 \mathrm{~K}$. Yellow and red line: tandem flight path of Falcon and Geophysica (except excursion to point E: Falcon only). Red flight legs: UTTCs detected remotely by Falcon lidar or in situ onboard Geophysica. Yellow flight legs: UTTCs either not present (parts between $\mathrm{A}$ and $\mathrm{B}$ and around $\mathrm{E}$ ) or not detectable because of heavy precipitation (B-C) or window icing (partly between $\mathrm{F}$ and G). UTTCs cover a region of $\sim 10^{5} \mathrm{~km}^{2}$ (D-E-F-G and on the way from $\mathrm{A}$ to $\mathrm{B}$ ) and persist at least $3 \mathrm{~h}$ (around $\mathrm{F}$ ).

\section{Measurements}

\subsection{Overview}

A total of seven scientific tandem flights were carried out during APE-THESEO, each 4-5 hours long, mostly employing the Falcon in the pathfinding mode. Figures $2-4$ give an overview over one of these coordinated flights, which took place on 24 February 1999. This flight aimed at investigating the microphysical properties of particle distributions in the TTL close to a deep convective system which was located about $950 \mathrm{~km}$ to the southwest of the Seychelles, see Fig. 2. In Fig. 3, the white curtain with cloud lidar images shows the Falcon measurements (flight level $\sim 10 \mathrm{~km}$ ) and the black line (with arrows) is the Geophysica flight path (flight levels $14-18 \mathrm{~km})$. In the vicinity of the tropical thunderstorm (from point B to C in Figs. 2 and 3), there are no lidar measurements due to heavy precipitation. On the other parts of the flight (C-D-F), an about $2 \mathrm{~km}$ thick visible cirrus deck was located between 12 to $14 \mathrm{~km}$, which was directly connected with the anvil of the thunderstorm and might in part be outflow from this system. At greater distances from the storm $(\mathrm{G})$ the visible cirrus cloud turns into an SVC layer at $\sim 14 \mathrm{~km}$. Distinct and extensive UTTC layers were detected above $17 \mathrm{~km}$ altitude. The UTTCs are separated from the anvil clouds and other cirrus by $3-4 \mathrm{~km}$ vertical distance. 


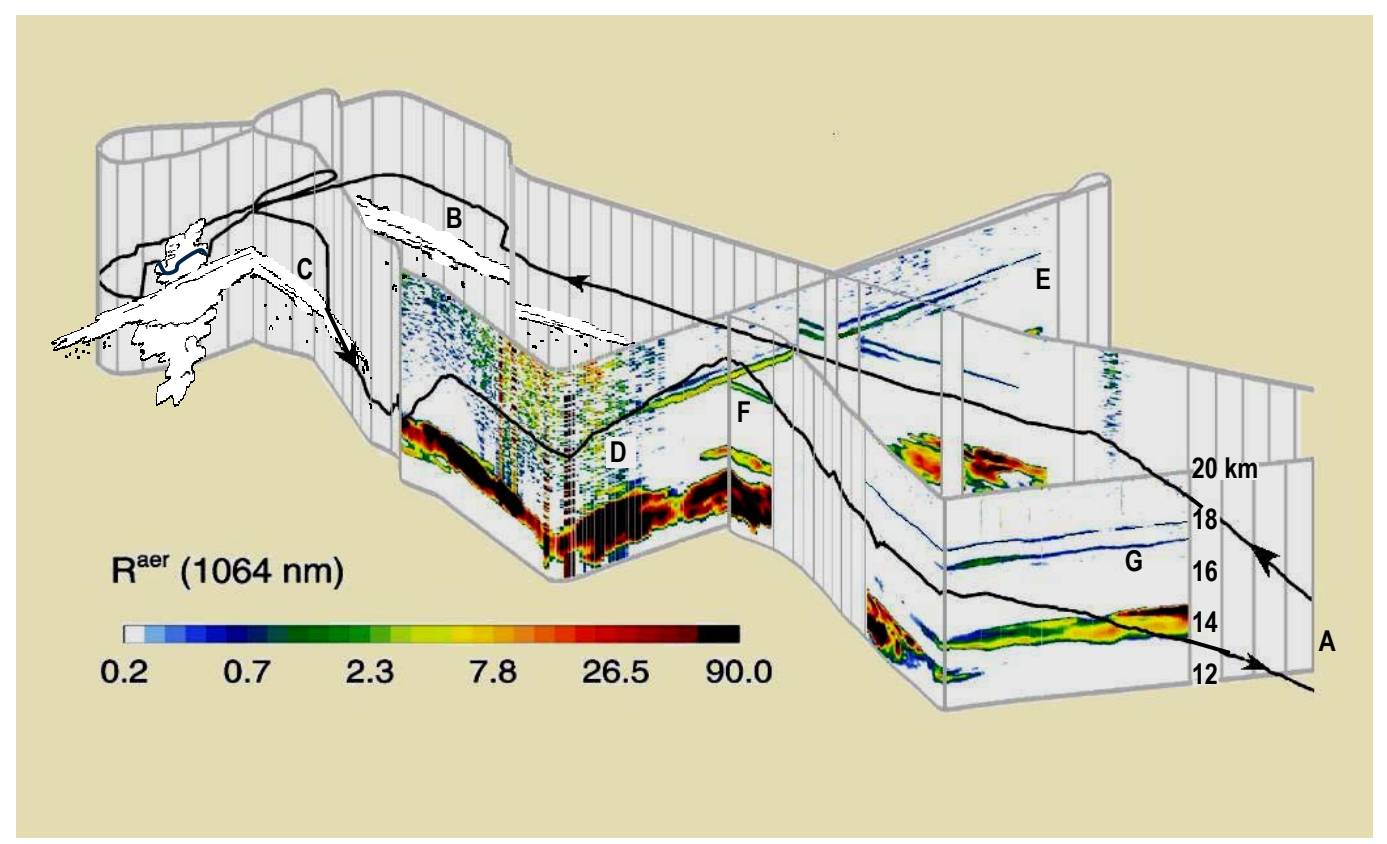

Fig. 3. Aerosol backscatter ratio at $1064 \mathrm{~nm}$ (i.e. $R^{\text {aer }}=R_{1064}-1=$ the backscatter coefficient of aerosol divided by that of cloud-free air) measured by OLEX on the Falcon on the same flight as in Fig. 2. The measurement curtain is shown from 12 to $20 \mathrm{~km}$ altitude. Periods with no measurements (either due to heavy precipitation in the vicinity of the $\mathrm{Cb}$ or due to window icing) are marked by gray vertical lines. The Geophysica flight path is marked as black curve. The Geophysica followed the Falcon initially with 30-45 min delay, but after a northward excursion of the Falcon (to E) was flying exactly above it (from F on within a few tens of meters in the horizontal direction).

They are also disconnected from the cumulonimbus turrets, which reached a maximum altitude of $15 \mathrm{~km}$, see Fig. 4 (see also Thomas et al., 2002). In some locations there is a UTTC double layer, probably related to a double tropopause (as often observed in the Seychelles radio sondes).

The general pattern of thicker clouds below $15 \mathrm{~km}$ and very thin clouds above $17 \mathrm{~km}$ altitude without direct connection corroborates the concept of the TTL: deep convection lifts large amounts of water to the lower edge of the TTL, but usually not deeply into it. Within the TTL the air rises slowly, mainly radiatively and without further convective drive. Cirrus clouds may form within the TTL and affect the water vapor budget. Though suggestive, this picture does not anticipate the mechanisms of dehydration in the TTL. Deep convection might lead to air masses overshooting the buoyancy equilibrium height (hyperventilation), and consequently to cooling far below ambient temperatures. Provided that ice crystals grow to sufficient sizes and manage to sediment out of these air masses before they sink back to the equilibrium buoyancy level (with concomitant heating), hyperventilation might lead to extremely dry air masses. This mechanism has first been advocated by Danielsen (1982) and is recently again promoted by Sherwood and Dessler (2000). Furthermore, Sherwood (2002) argues that condensation outside of convection does not reset the water vapor to a lower value independent of convective influence. Whether the ice particles in convective hyperventilation can grow to sizes large enough for rapid sedimentation is currently very unclear. On the other hand, the measurements described in this work in combination with cirrus cloud modeling lead Luo et al. (2003b) to conclude that UTTCs may indeed be the final step in the dehydration sequence through which air passes on its way from the lower troposphere to the stratosphere.

\subsection{Lidar measurement of UTTCs}

During APE-THESEO lidar measurements on board the Falcon were performed at $355 \mathrm{~nm}, 532 \mathrm{~nm}$ and $1064 \mathrm{~nm}$. In addition, at $532 \mathrm{~nm}$ the depolarization ratio is measured, which is an indicator for the shape of the particles (spherical droplets versus non-spherical crystals). Aerosol backscattering ratios@1064 nm within UTTCs are in the range 17 , while the cloud layers remain practically invisible at @ $532 \mathrm{~nm}, R_{532}^{\mathrm{aer}}<0.2$. This makes these particles hard to detect, and standard aerosol lidar measurements @ $532 \mathrm{~nm}$ from the ground require very long integration times or do not detect UTTCs at all. We performed ground measurements during night with the Falcon lidar @ 1064 nm, and an integration over several hours reveals the presence of the UTTCs as a faint signal below the tropopause.

In principle, it is easier to observe thin laminar clouds at the tropical tropopause when looking from above. The LITE experiment with an aerosol lidar@532nm onboard 


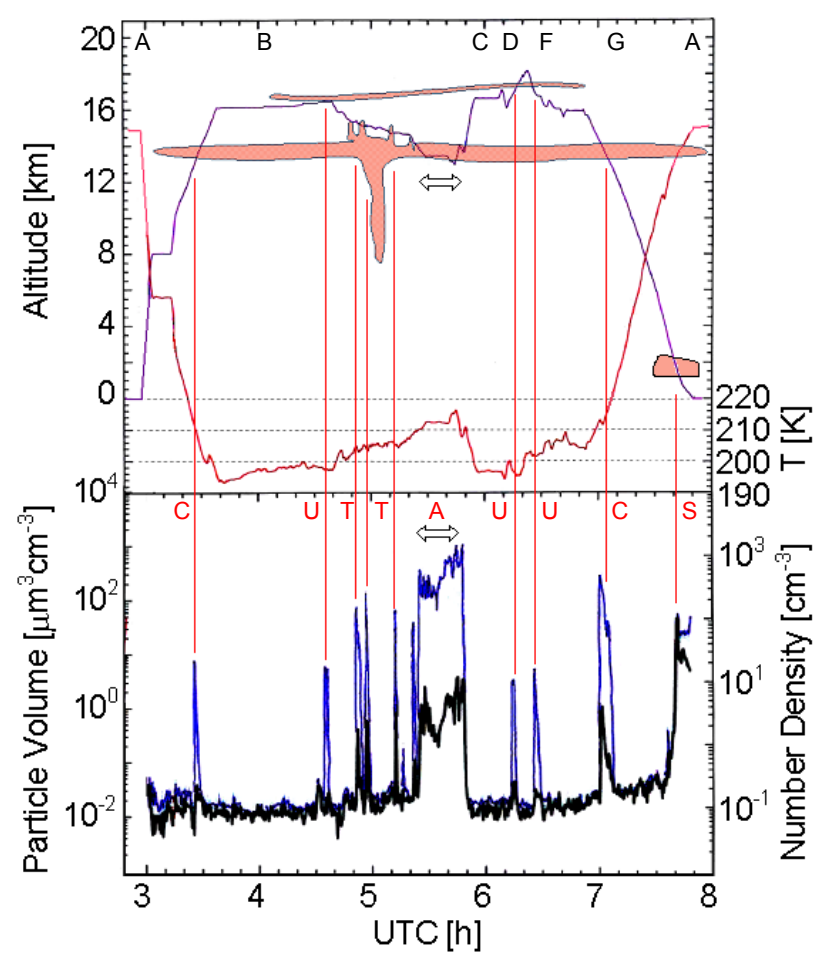

Fig. 4. In situ measurements onboard Geophysica on 24 February 1999, same flight as in Fig. 2 and 3. Upper panel: flight altitude (blue curve, left hand ordinate) and temperature (red curve, right hand ordinate) with a sketch of the cloud pattern as derived from the remote and in situ measurements. Lower panel: FSSP-300 particle volume (blue curve, left hand ordinate) and particle number density (black curve, right hand ordinate). Marks A-G in upper panel are equivalent to Fig. 2 and 3. Marks in lower panel: $\mathrm{C}=$ cirrus; $\mathrm{U}$ = UTTC; $\mathrm{T}=$ cumulonimbus turret; $\mathrm{A}=$ cirrus anvil; $\mathrm{S}=$ stratus cloud.

the space shuttle has demonstrated the existence of extensive laminar cirrus in the tropics all around the globe (Winker and Trepte, 1998). The clouds seen by LITE are of similar thickness and altitude as UTTCs, but they find $R_{532}^{\text {aer }} \approx 3$, and consequently the optical thickness of these clouds is typically one order of magnitude higher than UTTCs. Therefore, UTTCs would probably not be visible for LITE.

While on 24 February 1999 UTTCs are clearly discernible in the in situ data and the $1064 \mathrm{~nm}$ lidar backscatter (Figs. 3 and 4), the $532 \mathrm{~nm}$ backscatter and depolarization data are often noisy because thicker cirrus between the aircraft and the UTTC lead to additional weakening of the in any case small UTTC signal (the Rayleigh signal from molecular scatterers is 16 times stronger at $532 \mathrm{~nm}$ than at $1064 \mathrm{~nm}$ ). However, during a later flight on 27 February 1999 UTTCs were measured remotely without other clouds disturbing the observation, see Fig. 5. The total backscattering ratios@ $532 \mathrm{~nm}$ are smaller than 1.3, with a volume depolarization coefficient of 2-4\%. The optical thickness @ $1064 \mathrm{~nm}$ of UTTCs can be
Table 2. Statistics of the total of 19 hours of OLEX in-flight observations covering some $14000 \mathrm{~km}$ of flight distance. Clouds which are optically so thick that it cannot be judged whether or not a UTTC is above the cloud are not included in this statistics

\begin{tabular}{lc}
\hline $\begin{array}{l}19 \text { hours of airborne aerosol } \\
\text { lidar observations }\end{array}$ & Fraction of observations \\
\hline Thicker cirrus (visible or SVC) & $40 \%$ \\
without UTTCs & \\
Thicker cirrus and UTTCs & $19 \%$ \\
Only UTTCs, no thicker cirrus & $12 \%$ \\
Clear sky & $29 \%$ \\
\hline
\end{tabular}

estimated to range from $1.3 \times 10^{-4}$ to $8 \times 10^{-4}$ using a lidar coefficient of 80 (the ratio between the extinction coefficient to backscattering coefficient) obtained by a T-matrix calculation assuming that the ice particles are prolate spheroids with an aspect ratio ranging from 0.5 to 0.8 (Mishchenko, 1991; Carslaw et al., 1998). The aerosol backscattering ratios at shorter wavelengths $(532 \mathrm{~nm}$ and $355 \mathrm{~nm})$ are much smaller and are hardly distinguishable from the background. The small backscattering ratios @ $532 \mathrm{~nm}$ is corroborated by in situ measurements onboard Geophysica performed by the sideways-looking scatterometer MAS $R_{532}^{\text {aer }}<0.2$.

From Figs. 2, 3 and 5 based on lidar measurements the following characteristics of the UTTCs may be summarized:

(a) The clouds are located only a few hundred meters below the tropical cold point tropopause with a vertical thickness of only 200-300 m, making them prime candidates for the last dehydration step of air during troposphereto-stratosphere exchange.

(b) Their horizontal extension is several thousands of square kilometers.

(c) Aerosol backscattering ratios of UTTCs are extremely low $\left(R_{1064}^{\mathrm{aer}}=1-7, R_{532}^{\mathrm{aer}}<0.2\right)$, which makes these clouds currently best accessible by aircraft-borne lidar measurements@1064nm.

(d) The lidar signal @ $532 \mathrm{~nm}$ of the UTTCs shows an aerosol depolarization signal of 10-30\% from both OLEX (remotely from the Falcon) and MAS (in situ on Geophysica), indicating particles are of non-spherical shape.

(e) Within UTTCs, the backscattering ratio is relatively homogeneous, despite the small backscattering ratio, calling for a non-trivial stabilization mechanism (Luo et al., 2003a).

(f) During the total of 19 hours of OLEX in-flight observations on 7 mission flights, the UTTC coverage was $31 \%$, see Table 2 for more statistical information. 


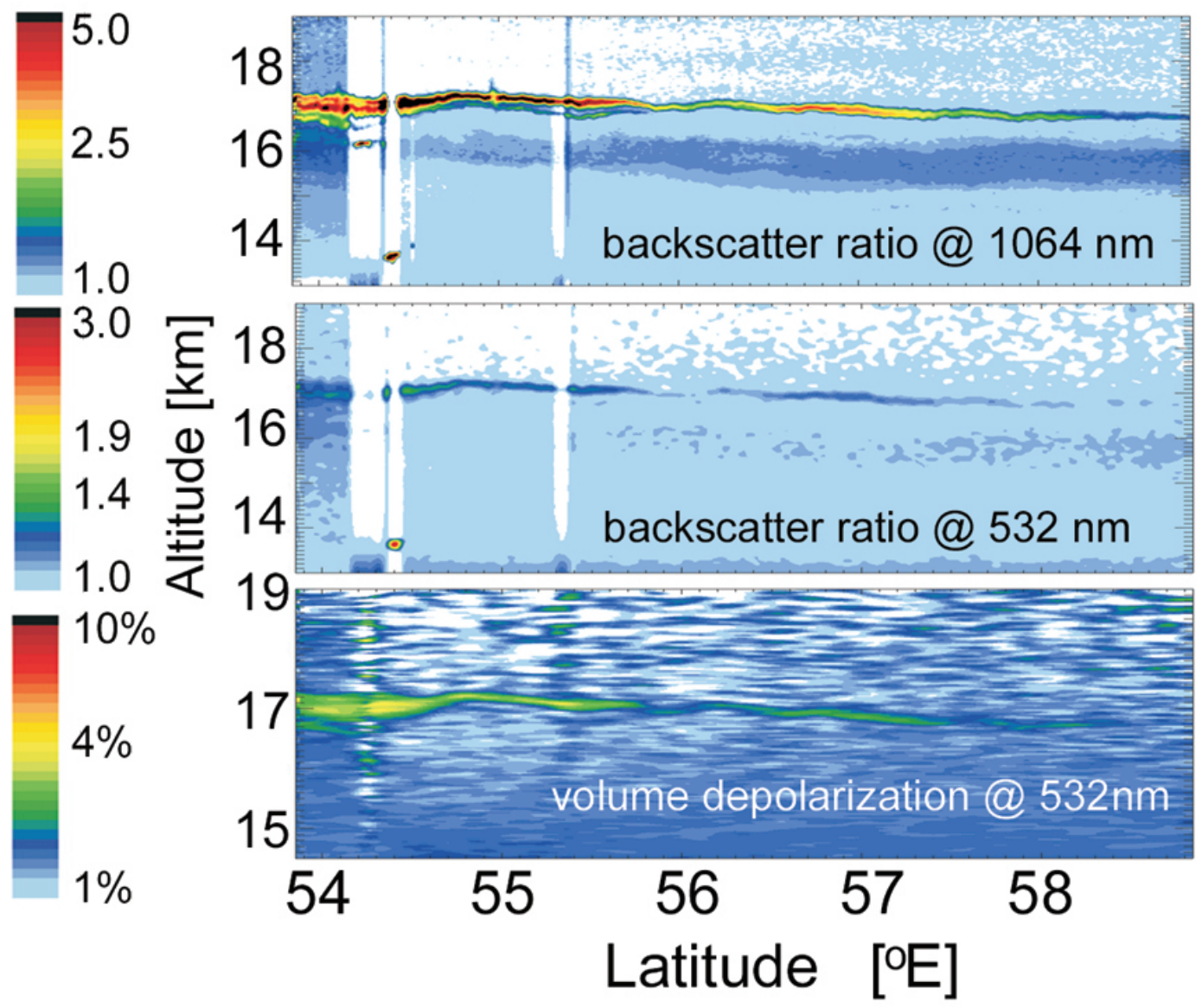

Fig. 5. Lidar measurements during another APE-THESEO flight on 27 February 1999. Backscattering ratios at $1064 \mathrm{~nm}$ and $532 \mathrm{~nm}$ and volume depolarization at $532 \mathrm{~nm}$ measured by OLEX on the Falcon.

\subsection{In situ measurements}

One section of the extensive UTTC shown in Figs. 2-4 is also shown in Fig. 6a, together with results from the in situ total water measurements (FISH) and the particle counter measurements (FSSP-300) on board of the Geophysica in Fig. 6b. The total water, measured by the Ly- $\alpha$ hygrometer FISH, is shown by the solid line. Extremely low water mixing ratios were found in the tropical tropopause region (2.0-2.5 ppmv in the cloud free areas). Subtracting the gas phase (obtained from the cloud-free areas) from the total $\mathrm{H}_{2} \mathrm{O}$ pressure measured by FISH and averaging over the cloud altitude ranges (identified by FSSP, dashed line) yields about 100 ppbv of $\mathrm{H}_{2} \mathrm{O}$ in the condensed phase, after accounting for oversampling of particulate water in the cloud particles by a factor of $\sim 5$ (particle oversampling is a common property of forward looking hygrometers on aircraft, without which the cloud water could not be determined; the oversampling factor is estimated from the aerodynamic properties of the inlet configuration). The FSSP-300 measurements (Fig. $6 \mathrm{~b}$ and 7) show a sudden increase in total particle volume when entering a UTTC. The FSSP-300 size distributions of UTTCs show a distinct particle mode around $r \approx 5-6 \mu \mathrm{m}$ and particle number densities of 5-10 particles per liter for $r>3 \mu \mathrm{m}$ (Fig. 7), which are responsible for the measured high particulate volume. The volume density measured by the FSSP-300 corresponds to a water vapor mixing ratio that condensed in the particulate phase of $\sim 40 \mathrm{ppbv}$, which is in fair agreement with the FISH measurement (the origin of the factor 2.5 discrepancy is not known, but given the accuracies of both instruments this discrepancy is quite acceptable).

Given the small fraction of only $1-5 \%$ of the total water residing in the condensed phase the identification of the UTTCs as water ice particles must be questioned. An alternative identification as nitric acid containing particles, e.g. nitric acid trihydrate (NAT $\equiv \mathrm{HNO}_{3} \cdot 3 \mathrm{H}_{2} \mathrm{O}$ ) as known from polar stratospheric clouds, would automatically result in very small amounts of condensate, as there is only a limited amount of $\mathrm{HNO}_{3}$ at the tropical tropopause. The existence of NAT at the tropical tropopause has been suggested by Hervig and McHugh (2002). However, Luo et al. (2003a,b) address this question specifically and conclude that the UTTC particles consist indeed of water ice. This conclusion is, besides 


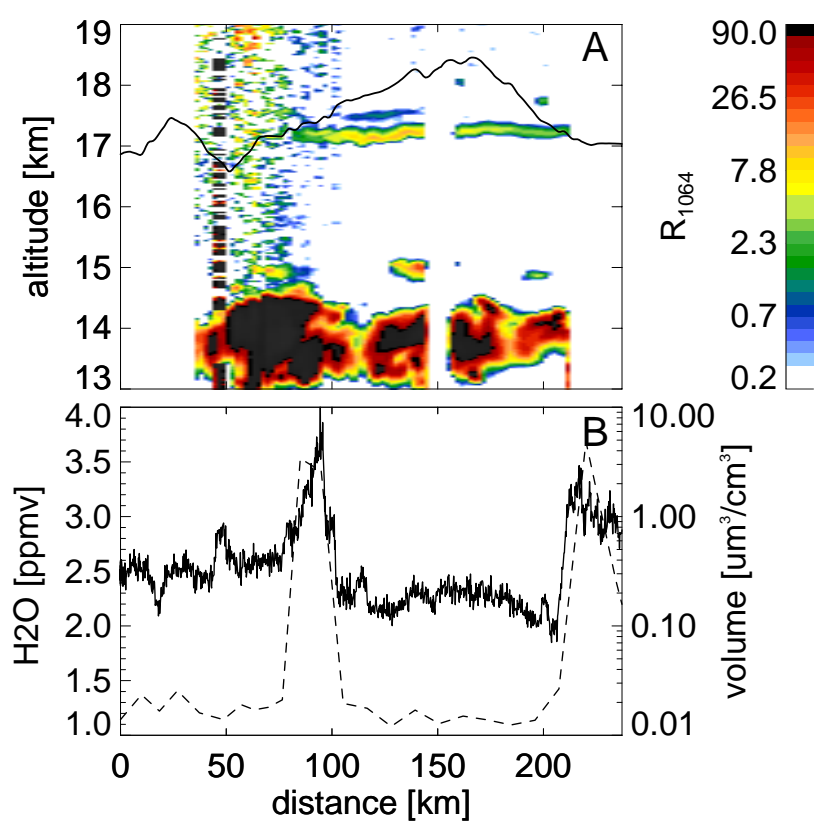

Fig. 6. Simultaneous lidar and in situ measurements of the UTTCs between points $\mathrm{D}$ and $\mathrm{F}$ in Fig. 3. Panel A: the cloud lidar backscattering ratio @ $1064 \mathrm{~nm}$. The black line shows the flight route of the Geophysica aircraft. Panel B: in situ measurements on board of Geophysica. Dashed line: volume in condensed phase measured by the FSSP-300 (right hand ordinate). Solid line: total water measured by the hygrometer FISH (which oversamples particulate water by a factor of 5 , left hand ordinate).

other arguments, corroborated by the counter-flow virtual impactor (CVI) measurements onboard of the Geophysica. The CVI has an integrated tunable diode laser spectrometer (CVI-TDL) for the measurement of $\mathrm{HNO}_{3}$ in the particulate phase, but the instrument showed practically no particulate nitric acid during the campaign (not shown here, see Luo et al., 2003b), except for one flight into a tropical cyclone.

Vertical profiles of the in-situ measurements are shown in the companion paper (Luo et al., 2003a). On 24 January 1999 the tropopause over the western Indian ocean was extremely cold $(T \approx 188 \mathrm{~K})$ with a height of about $17.5 \mathrm{~km}$. The UTTCs indicated by an enhancement in the ice volume were located at about $17.1 \mathrm{~km}, 400 \mathrm{~m}$ below the cold point tropopause. The air was subsaturated with respect to ice below the UTTCs and supersaturated above the UTTCs. In the cloud layer, the air was in equilibrium with ice. This observation is important to explain the stability of these thin cloud layers, as we discuss in detail in the companion paper (Luo et al., 2003a).

\subsection{Determination of UTTC condensed mass from lidar measurements}

The water mixing ratios, that condensed in the UTTCs, can also be estimated from the remote sensing lidar measurement

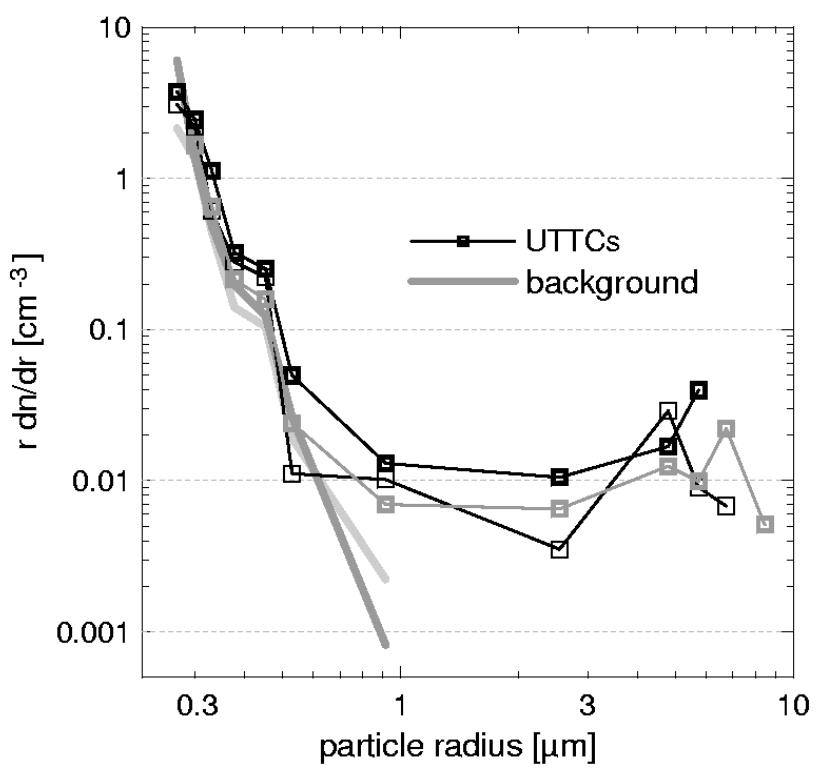

Fig. 7. Particle size distributions as function of (equivalent sphere) radius $r$ measured by the FSSP-300 on board of Geophysica on 24 February 1999. Open squares: measurements inside UTTCs from several cloud encounters (see Fig. 4 and Fig. 3 between points D and F). Lines without symbol: background aerosols in the immediate vicinity below or above UTTCs.

using the T-matrix method for the backscattering coefficients (Mishchenko,1991, Carslaw et al., 1998). The simulated lidar backscattering ratio @ 1064 of 1 ppbv $\mathrm{H}_{2} \mathrm{O}$ condensed in ice particles is shown in Fig. 8. A temperature of $190 \mathrm{~K}$ is used for the calculation of the molecular number density of air. The size of the UTTC particles is 5-6 $\mu \mathrm{m}$ according to the in situ FSSP measurement. For particles with this size the lidar backscattering ratio of $1 \mathrm{ppbv}$ of ice ranges from 0.04 to 0.2 , depending on the aspect ratio (ratio between the axes perpendicular and parallel to the rotational symmetry). This leads to an ice water content of 5 to $25 \mathrm{ppbv}$ for a cloud with backscattering ratio of unity @ $1064 \mathrm{~nm}$. For the observed UTTCs with $R_{1064}^{\mathrm{aer}}=1-7$, this results in about 25 $170 \mathrm{ppbv}$ of $\mathrm{H}_{2} \mathrm{O}$ that condensed as ice (for aspherical particles with aspect ratio $=0.5$ ) or 5-70 ppbv (for nearly spherical or oblate particles). The same cloud was also sampled by the in situ instruments (Fig. 6), showing an ice water content of 40-100 ppbv. The ice water content of $25-170 \mathrm{ppbv}$ obtained from the lidar measurements, consistent with the in situ data, provided an aspect ratio of 0.5 for the ice particles is assumed. A more spherical shape (aspect ratio $>0.5$ ) would lead to less ice water content. The analysis above suggests that the ice particles with $r \approx 5 \mu \mathrm{m}$ may have a highly non-spherical shape. In the flight on 27 February 1999, even lower aerosol lidar backscatter ratios @ 1064 nm (1-2) over a larger area were found, indicating that the ice water content 


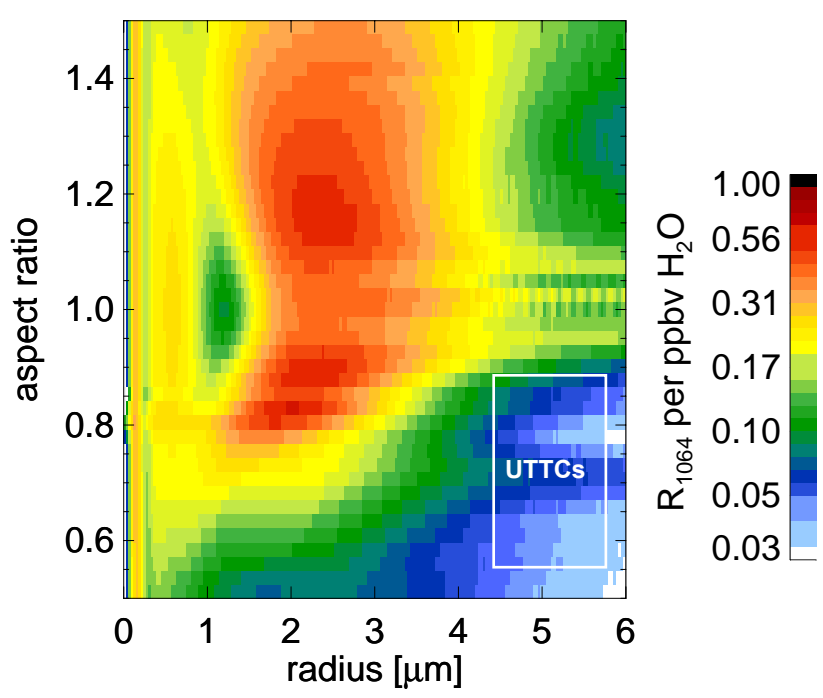

Fig. 8. Aerosol lidar backscattering ratio of $1 \mathrm{ppbv} \mathrm{H}_{2} \mathrm{O}$ condensed as ice particles with radius and asphericity as indicated on the axes (aspect ratio defined as ratio between the axes perpendicular and parallel to the rotational symmetry). The aerosol backscatter is calculated by using the T-matrix method (Mishchenko, 1991) assuming that the particles are spheroids. The backscattering ratio can be scaled to other ice water content by just multiplying the scale shown in the right hand side by the amount of the actual ice water content in ppbv. The radius given here is the mode radius (equivalent sphere) of a lognormal size distribution with mode width $\sigma=$ 1.20. The white box in the lower right corner indicates the region of interest for UTTCs.

can be as low as 25 ppbv.

Hence, the three independent instruments agree with each other within a factor of 2.5 , providing strong evidence that the total amount of condensed phase water is very small, 25100 ppbv.

\section{Summary}

UTTCs have the following characteristics: (i) the coverage of these clouds was found to be high (31\%) during the APETHESEO campaign in February/March 1999 in the western Indian Ocean; (ii) the vertical thickness of UTTCs are only 200-300 m; (iii) they reside only a few hundred meters below the cold point tropopause; (iv) their horizontal extent may reach thousands of square kilometers; (v) the inside of the cloud layer is characterized by a high degree of homogeneity; (vi) they consist of water ice particles with a condensed matter in the cloud particles of $25-100$ ppbv $\mathrm{H}_{2} \mathrm{O}$, corresponding to only $1-5 \%$ of the total available water vapor; (vii) ice crystal radii are 5-6 $\mu \mathrm{m}$, number densities $5-10 \mathrm{~L}^{-1}$.

The high degree of homogeneity, the large geographic extent and the faint nature of UTTCs requires a stabilization mechanism, which is not necessary or known for other kinds of clouds. This is treated in detail in the companion paper (Luo et al., 2003a). The unique combination of high altitude and low number density makes UTTCs highly suited to serve as drying agent during the last step of dehydration of air directly before troposphere-to-stratosphere exchange. Luo et al. (2003b) investigate the conditions under which UTTCs serve this purpose. They conclude, that UTTCs are likely to yield a lowering of 0.35 ppmv of $\mathrm{H}_{2} \mathrm{O}$ in the air exchanged from the troposphere to the stratosphere in the tropics.

Acknowledgements. We are grateful to Stefano Balestri (APE) and Heinz Finkenzeller (DLR) for their organizational and infrastructural work, without which the campaign would not have taken place. We thank the pilots on both aircraft, Marcus Scherdel, Stefan Grillenbeck, Oleg Chtchepetkov and Alexander Bestchastnov, for their extremely flexible approach to even the most difficult tasks. Further we thank Gilbert Faure (Director General of Civil Aviation) and Alain Volcere (Airport Manager - operations - DCA Seychelles) of the Seychelles Airport authorities for their unbureaucratic support in all phases of the campaign. We are grateful to Adrian Tompkins at ECMWF and Marcia Baker at the University of Washington for fruitful discussions. Finally, we thank the European Commission for funding the APE-THESEO campaign, and several national agencies for additional support.

\section{References}

Carslaw, K. S., Wirth, M., Tsias, A., Luo, B. P., Dörnbrack, A., Leutbecher, M., Volkert, H., Renger, W., Bacmeister, J. T., and Peter, Th.: Particle microphysics and chemistry in remotely observed mountain polar stratospheric clouds, J. Geophys. Res., 100, 5785-5796, 1998.

Danielsen, E. F.: A dehydration mechanism for the stratosphere, Geophys. Res. Lett., 9, 605-608, 1982.

Gettelman, A., Holton, J. R., and Douglass, A. R.: Simulations of water vapor in the lower stratosphere and upper troposphere, J. Geophys. Res., 105, 9003-9023, 2000.

Hervig, M. and McHugh, M.: Tropical Nitric Acid Clouds, Geophys. Res. Lett., 29, 10.1029/2001GL014271, 2002.

Heymsfield, A. J.:, Ice particles observed in a cirriform cloud at $-85^{\circ} \mathrm{C}$ and implications for polar stratospheric clouds, J. Atmos. Sci., 43, 851-855, 1986.

Heymsfield, A. J. and McFarquhar, G. M.: high albedos of cirrus in the tropical Pacific warm pool: Microphysical interpretations from CEPEX and from Kwajalein, Marshall islands, J. Atmos. Sci., 53, 2424-2245, 1996.

Jensen, E. J., Toon, O. B., Pfister, L., and Selkirk, H. B.: Dehydration of the upper troposphere and lower stratosphere by subvisible cirrus clouds near the tropical tropopause, Geophys. Res. Lett., 23, 825-828, 1996.

Jensen, E. J., Pfister, L., Ackerman, A. S., Toon, O. B., and Tabazadeh, A.: A conceptual model of the dehydration of air due to freeze-drying by optically thin, laminar cirrus rising slowly across the tropical tropopause, J. Geophys. Res., 106, $17237-$ $17252,2001$.

Lohmann, U. and Roeckner, E.: Influence of cirrus cloud radiative forcing on climate and climate sensitivity in a general circulation model, J. Geophys. Res., 100 , 16305-16324, 1995. 
Luo, B. P., Peter, Th., Wernli, H., et al.: Ultrathin Tropical Tropopause Clouds (UTTCs): II. Stabilization and Destabilization Mechanisms, Atmos. Chem. Phys., this issue, 2003a.

Luo, B. P., Peter, Th., Fueglistaler, S., et al.: Dehydration potential of ultrathin clouds at the tropical tropopause, Geophys. Res. Lett., 30, doi : 10.1029/2002GL016737, 2003b.

Mishchenko, M. I.: Light scattering by randomly oriented axially symmetric particles, J. Opt. Soc. Am., 8, 871-882, 1991.

McFaquhar, G. M., Heymsfield, A. J., Spinhirne, J., and Hart, B.: Thin and subvisual tropopause tropical cirrus: Observations and radiative impacts, J. Atmos. Sci., 57, 1841-1853, 2000.

Omar, A. H. and Gardner, C. S.: Observation by the Lidar In-Space Technology Experiment (LITE) of high altitude cirrus clouds over the equator in regions exhibiting extremely cold temperatures, J. Geophys. Res., 106, 1227-1236, 2001.

Peter, Th., Meilinger, S. K., and Carslaw, K. S.: Quasi-Lagrangian Measurements of Clouds at and above the Tropopause, SPARC Newsletter No. 12, 2000.

Santacesaria, V., Carla, R., MacKenzie, R. A., Adriani, A., Cairo, F., Didonfrancesco, G., Kiemle, C., Redaelli, G., Beuermann, J., Schiller, C., Peter, Th., Luo, B. P., Wernli, H., Ravegnani, F., Ulanovsky, A., Yushkov, V., Sitnikov, N., Balestri, S., and Stefanutti, L.: Clouds at the tropical tropopause: a case study during the APE-THESEO campaign over the western Indian Ocean, J. Geophys. Res., 108, 10.1029/2002JD002166, 2003.

Sassen, K., Griffin, M. K., and Dodd, G. C.: Optical-scattering and microphysical properties of subvisual cirrus clouds, and climate implications, J. Appl. Meteorol., 28, 91-98, 1989.

Sherwood, S. C. and Dessler, A. E.: On the control of stratospheric humidity, Geophy. Res. Lett., 27, 2513-2516, 2000.

Sherwood, S. C.: A Microphysical Connection Among Biomass Burning, Cumulus Clouds, and Stratospheric Moisture, Science, 295, 1272-1275, 2002.

Stefanutti, L., Sokolov, L., Balestri, S., MacKenzie, A. R., and Khattatov, V.: The M-55 Geophysica as a platform for the Airborne Polar Experiment, J. Ocean Atm. Tech., 16, 1303-1312, 1999.

Thomas, A., Borrmann, S., Kiemle, Ch., Cairo, F., Volk, M., Beuermann, J., Lepuchov, B., Santacesaria, V., Matthey, R., Rudakov, V., Yushkov, V., MacKenzie, A. R., and Stefanutti, L.: In situ measurements of background aerosol and subvisible cirrus in the tropical tropopause region, J. Geophys. Res., 107, 2001 jd001385, 2002.

Wang, P. H., Minnis, P., McCormick, M. P., Kent, G. S., Yue, G. K., Young, D. F., and Skeens, K. M.: A study of the vertical structure of tropical $\left(20^{\circ} \mathrm{S}-20^{\circ} \mathrm{N}\right)$ optically thin clouds from SAGE II observations, Atmos. Res., 47/48, 599-614, 1998.

Winker, D. M. and Trepte, C. R.: Laminar cirrus observed near the tropical tropopause by LITE, Geophys. Res. Lett., 25, 33513354, 1998.

Wirth, M. and Renger, W.: Evidence of large scale ozone depletion within the Arctic polar vortex 94/95 based on airborne LIDAR measurements, Geophys. Res. Lett., 23, 813-816, 1996. 